\title{
ENTREVISTA COM W. LEO WETZELS
}

\author{
Ana Lívia Agostinho | Lattes | a.agostinho@ufsc.br \\ Universidade Federal de Santa Catarina
}

Núbia Ferreira Rech | Lattes | nubiarech@uol.com.br

Universidade Federal de Santa Catarina

W. Leo Wetzels é professor titular emérito da Vrije Universiteit Amsterdam, na Holanda, e professor titular da Universidade Federal do Ceará. Mestre pela Nijmegen University, na Holanda, em Linguística Geral e em Língua e Literatura Francesa em 1975, doutorou-se em 1981 em Linguística pela mesma universidade. Em 2014, recebeu o título de Doutor Honoris Causa da Pontifícia Universidade Católica do Rio Grande do Sul. Lecionou em universidades de vários países, tais como Nijmegen University; CNRS/ Sorbonne-Nouvelle, Paris; Universidad Internacional Menéndez Pelayo, Madrid; Universidad San Francisco, Quito, Peru. Passou três semestres em Harvard como pesquisador visitante e, como pesquisador convidado, participa de um projeto da École des Hautes Études en Sciences Sociales em Paris, onde prepara a edição impressa e digital das anotações de campo de Claude Lévi-Strauss durante sua segunda expedição no Brasil Central em 1938 e 1939. No Brasil, atuou como professor e pesquisador visitante em diversas universidades: Universidade Federal de Santa Catarina, Universidade Federal da Bahia, Universidade Estadual de Campinas, Universidade Federal do Rio Grande do Sul, Universidade Federal do Rio de Janeiro, Universidade de São Paulo, Universidade Federal de Rondônia, Universidade Federal de Alagoas, Universidade Federal da Paraíba, Universidade Federal do Ceará, Pontifícia Universidade Católica do Rio Grande do Sul, Universidade Federal de Goiás, Universidade Federal de Pernambuco, Universidade Federal do Pará, Universidade de Brasília.

Sua obra compreende mais de 20 livros como autor e editor, 37 capítulos de livros, mais de 30 artigos científicos, entre outros tipos de publicação. Editou, recentemente, juntamente com Sergio Menuzzi e João Costa, o volume "The Handbook of Portuguese Linguistics”, sobre o qual comenta ao fim da entrevista. Atua principalmente na área de Teoria e Análise Linguística de línguas indígenas brasileiras e português brasileiro, com enfoque nos estudos fonológicos e morfológicos, sendo um dos autores mais importantes da área. Orientou e coorientou mais de 30 teses de doutorado na Holanda e no 
Brasil. É fundador e editor da Revista Probus, assistente-editor do International Journal of American Linguistics e membro de comitê editorial de diversas revistas e séries científicas, tais como, DELTA, Letras de Hoje e Brill's Studies in the Indigenous Languages of the Americas.

Agostinho, Rech: Como surgiu o interesse em estudar o português brasileiro?

W. Leo Wetzels: Em 1984, fui convidado para dar um curso de fonologia teórica na UFBA [Universidade Federal da Bahia]. Minha estadia em Salvador coincidiu com o I Encontro Nacional de Fonética e Fonologia da UFSC [Universidade Federal de Santa Catarina], em Florianópolis. Jean-Pierre Angenot aproveitou minha presença no Brasil e me convidou para dar uma palestra neste encontro. Em Florianópolis, conheci Gilles Istre, Luiz Carlos Cagliari e Leda Bisol. A convite de Gilles e Jean-Pierre, voltei à UFSC, em 1985, para oferecer um curso de fonologia no Programa de Pós-Graduação em Linguística daquela Universidade. Depois da minha estadia em Salvador, comecei a estudar a fonologia do português brasileiro e descobri que se tratava de um sistema complexo e interessante. Minha curiosidade era despertada e com isto meu interesse no PB [português brasileiro] virou um fato. Os encontros que tive com Luiz Carlos Cagliari, Leda Bisol e, mais tarde, com João Moraes, todos eles excelentes linguistas e de espírito acadêmico aberto, fortaleceram a minha decisão de dedicar uma parte do meu tempo e de minha atenção ao estudo do PB.

Agostinho, Rech: Durante sua carreira, você manteve diversas parcerias com pesquisadores e universidades brasileiras. Você poderia nos contar um pouco sobre suas parcerias no Brasil?

W. Leo Wetzels: Desde 1984, fiz uma centena de viagens para o Brasil. Dei aulas como professor visitante em vários lugares, recebendo apoio do $\mathrm{CNPq}$ [Conselho Nacional de Desenvolvimento Científico e Tecnológico], da CAPES [Coordenação de Aperfeiçoamento de Pessoal de Nível Superior], da FAPESP [Fundação de Amparo à Pesquisa do Estado de São Paulo], da UFPE [Universidade Federal de Pernambuco] e da ABRALIN [Associação Brasileira de Linguística]. Depois da primeira visita a Florianópolis, voltei mais uma vez para a UFSC, convidado pelos colegas Ruth Lopes e Emílio Pagotto, em 1995. Antes e depois disso, trabalhei na Unicamp [Universidade 
Estadual de Campinas], no Museu Nacional, na USP (Universidade Estadual de São Paulo], na PUCRS [Pontifícia Universidade Católica do Rio Grande do Sul], e em outras universidades brasileiras. Recentemente aceitei uma vaga de professor visitante da UFC [Universidade Federal do Ceará]. A fonologia é pouco praticada em certas universidades do Norte e Nordeste brasileiro, sendo a UFC uma delas. Diante disto, espero que minha atuação possa estimular um grupo de estudantes em Fortaleza para a fonologia. Stella Telles (UFPE) foi a primeira aluna brasileira que se formou sob a minha orientação, em 2002, como especialista em línguas Nambikwara. Stella foi a primeira de um grupo de 25 estudantes sul-americanos que defenderiam uma tese de doutorado em Amsterdam. Adorei trabalhar com os jovens linguistas, os quais favoreceram uma grande oportunidade de intercâmbio de conhecimentos que muito enriqueceu minha vida profissional e pessoal.

Agostinho, Rech: Em diversas publicações você se dedicou ao estudo do acento no português brasileiro, um tema controverso dentro da fonologia sobre essa variedade. Como você vê os estudos mais recentes sobre esse assunto?

W. Leo Wetzels: Existe um número considerável de assuntos fonológicos, ou linguísticos em geral, sobre os quais os linguistas discordam. Como vocês dizem, o acento em português é um deles. Aliás, o PB não tem a exclusividade desta controvérsia: a mesma diferença de opinião existe com relação ao espanhol e ao catalão (Antonio Grau Sempere (2006) dedicou sua dissertação a esta questão). Como é sabido, a principal discordância diz respeito ao papel do peso silábico na atribuição do acento primário do $\mathrm{PB}$. Nos meus trabalhos, mostrei que os argumentos tipológicos então utilizados na literatura gerativa para desqualificar a ideia de que a (maior) quantidade silábica era responsável pela atração do acento em certas línguas românicas não eram válidos (WETZELS, 2003). Concluí que a questão devia ser debatida com base em argumentos internos provenientes das próprias línguas românicas. Consequentemente, a discussão sobre a natureza do acento do PB me parecia aberta e não fechada. Na sequência das discussões, considerei que o acento em nomes e adjetivos não derivados era sensível à quantidade e que existiam apenas três padrões acentuais realmente produtivos nessas categorias lexicais. Estes são os padrões que os falantes nativos seguem espontaneamente frente a palavras novas num ambiente não experimental: as palavras oxítonas, quando terminam em uma sílaba pesada (calor); as palavras paroxítonas, quando terminam em uma sílaba aberta (cabeça), e as palavras 
proparoxítonas, quando terminam numa sequência do tipo $\{\mathrm{i}, \mathrm{u}\} \mathrm{V}$ (critério, ingênuo). Todos os outros padrões são raramente criados espontaneamente, pelo menos nos tipos de palavras novas identificadas em Hermans e Wetzels (2012).

Agostinho, Rech: Na sua opinião, quais são os desafios atuais para os estudos fonológicos do português brasileiro?

W. Leo Wetzels: Uma das coisas que me intrigam é a diferença relativamente grande entre o português normativo das grandes cidades, que, no seu conjunto, embora às vezes com diferenças marcantes, representa o que poderíamos considerar uma norma global, e o português rural, que também aparenta ser homogêneo ao longo da grande extensão territorial do Brasil, além de compartilhar muitas características com a fala das classes econômicas menos favorecidas que vivem nas cidades. Listando essas diferenças e considerando que a fonologia de uma língua forma uma gramática que contém as generalizações e suas interações relevantes sobre a estrutura sonora das palavras e frases, sinto-me inclinado a pensar que estamos lidando com gramáticas diferentes. Se vocês me permitirem voltar à discussão sobre o acento, por exemplo, parece que na variante rural o princípio do "acento na última sílaba pesada" se limita, cada vez mais, aos não verbos que terminam em ditongo, devido à erosão das consoantes finais da sílaba, dentro e no final da palavra, pelo menos ao nível fonético. Isto ocorre especialmente em áreas onde estas regras se aplicam (quase) obrigatoriamente e onde a marca do plural se realiza quase que sistematicamente nos morfemas pré-nominais. Aqui, o princípio do "acento-para-penúltima-mora" está perdendo espaço para o princípio do "peso para acento (lexicalizado?)", sob a forma de uma regra que prolonga as vogais acentuadas em sílabas abertas. Seria interessante analisar integralmente a fala dessas variantes rurais, sobretudo a de pessoas sem ou com baixa escolaridade, considerando a fala "rural" como um sistema fechado, e construir uma gramática fonológica observando também a sua interação com a morfologia para obter uma visão integral de quais diferenças estruturais poderiam existir com relação à grámatica das pessoas falantes da norma.

Agostinho, Rech: Você acha que a fonologia tem enfrentado uma crise teórica? Quais são os impasses e desafios da área atualmente?

W. Leo Wetzels: Com The Sound Pattern of English (CHOMSKY; HALLE, 1968), o propósito da fonologia teórica foi apresentar a estrutura sonora de uma língua como uma 
gramática gerativa explícita, em que as diferentes variantes de um morfema são derivadas de uma sequência lexical única, através de derivações que consistem em regras ordenadas específicas da língua descrita. Inicialmente, a ênfase estava nos aspectos formais das regras e estruturas e na maneira pela qual a escolha entre possíveis gramáticas para a língua $\mathrm{X}$ tinha que ser feita, através de um critério de simplicidade desenvolvido pela teoria. Isso rapidamente levou à questão de saber até que ponto o modelo teórico assim desenvolvido poderia ser interpretado como um modelo realista em relação ao modo como o falante organiza mentalmente o conhecimento da estrutura sonora de sua língua. A questão é bem resumida no título de um capítulo escrito por Paul Kiparsky "How Abstract is Phonology”, presente num volume publicado por Fujimura (1973). A interação opaca de regras faz parte do problema da abstração e diz respeito ao fato de que segmentos fonológicos lexicais ou generalizações fonológicas expressas por regras (ordenadas) são invisíveis nas estruturas de superfície derivadas pela gramática. Na perspectiva da aquisição da língua pelas crianças, alguns fonólogos "naturalistas" tomaram a posição de que certas regras ou interações de regras opacas não podiam ser aprendidas. As tentativas de eliminar a abstração demasiada da teoria levaram a uma série de variantes da "fonologia natural", das quais a mais conhecida, "Natural Phonology", desenvolvida por Theo Vennemann e Joan Hooper [Bybee] (ver especialmente Hooper (1976)), foi muito popular entre os fonólogos brasileiros durante bastante tempo. Enquanto que a fonologia derivacional não tinha problemas técnicos para derivar estruturas superficiais opacas, a TO [Teoria da Otimidade] clássica não consegue lidar com certos tipos de opacidade que ocorrem com frequência nas línguas. As tentativas de resolver este problema levaram ao desenvolvimento de várias variantes do modelo TO padrão (veja Gussenhoven e Jacobs (2017, p. 222-231), para uma breve discussão). Particularmente, as alternativas que foram propostas não me convencem. Além disso, o fato de a TO afirmar que as restrições são inatas torna difícil o seu alinhamento com o que se observa nas pesquisas, nas quais o número de restrições propostas cresceu fabulosamente e onde a existência de restrições que se negam mutualmente sequer suscita dúvidas entre os pesquisadores. Com a TO clássica, a questão da credibilidade da teoria como modelo realista do conhecimento linguístico dos falantes está de volta e, com ela, retorna também a pergunta se a fonologia teórica estará (de novo) em crise. Se você fizer a pergunta àqueles que acreditam que a TO, com suas reivindicações implícitas e explícitas, está no caminho certo, eles responderão que não há crise e que os problemas existentes são para serem resolvidos. Eu sou menos otimista, mas, no entanto, não usaria a palavra "crise" para caraterizar a situação, que não é 
diferente de alguns momentos da era pré-TO. Um novo paradigma geralmente constitui uma reação aos problemas do paradigma anterior. Na primeira fase, há principalmente a visão de que um grande passo a frente foi dado. Depois de algum tempo, quando as desvantagens da nova teoria são trazidas à luz, o entusiasmo inicial é enfraquecido. Temos de entender também que a duração do ciclo de vida de um paradigma depende, além da sua plausibilidade intrínsica, do status profissional dos proponentes da teoria, das possibilidades que a teoria oferece aos jovens linguistas para desenvolvê-la através de suas próprias contribuições, do poder político dos professores proponentes ou aderentes para colocar seus alunos em universidades de prestígio e da lealdade destes últimos às ideias de seus professores. Estes fatos são entre eles interligados e juntos podem levar à persistência de proposições duvidosas. Por outro lado, é verdade que certos fenômenos, expressos sob a forma de restrições ou como resultado da interação de restrições, ocorrem muito mais frequentemente do que outros. Isso, por exemplo, é evidente a partir do "surgimento do não marcado", um fenômeno recorrente na estrutura sonora das línguas e na TO claramente valorizado. Isso, a meu ver, não é ligado a hipótese de que todas as restrições propostas são inatas, e deixo aberta a possibilidade de que nenhuma restrição o seja. Portanto, não tenho nenhum problema em duvidar do caráter inato das restrições e, no mesmo tempo, usar a TO como modelo de análise. Além disto, prefiro trabalhar com um modelo "estratal" da gramática fonológica, com os componentes lexical e pós-lexical distintos, no qual a saída da fonologia lexical é a entrada para a pós-lexical. Em tal modelo, as formas opacas frequentemente se explicam pela interação desses componentes (veja Bermúdez-Otero (2018; no prelo) para um modelo TO estratal).

De modo geral, as teorias nos forçam a refletir e a entrar na discussão com os colegas. Além disto, como já disse, há uma lógica nas mudanças teóricas, pelo fato de que normalmente uma nova teoria evita (uma parte d)as insuficiências da prévia. $\mathrm{Na}$ TO a descrição estrutural de uma regra está dissociada da mudança estrutural. Assim, com relação a uma regra como $\varnothing \rightarrow \mathrm{C} / \mathrm{V} \_\mathrm{V}$ (ou VV $\rightarrow \mathrm{VCV}$ ), a descrição estrutural VV se transforma na restrição de marcação *VV, que define o hiato como estrutura marcada. Pelo lugar dela numa sequência de restrições de fidelidade, a gramática da língua "desmarca" (ou não) a sequência VV, por exemplo, pela epêntese de C, pelo apagamento de uma das Vs, pela fusão das duas Vs, etc. Em termos muito gerais, seguindo as grandes etapas da teoria fonológica percorridas desde o estruturalismo, podemos dizer que as mudanças teóricas envolviam a concepção da fonologia como uma (sub)gramática explícita que deriva formas superficiais a partir de formas lexicias; que a fonologia lexical incentivou a reflexão 
sobre a interação entre fonologia e morfologia; que a fonologia métrica contribuiu para o melhor entendimento dos tipos de acento e do ritmo; que as fonologias autossegmental e da geometria dos traços ensinaram bastante sobre as representações fonológicas lexicais e derivadas, inclusive quanto à existência de traços fonológicos funcionando como morfemas e do fenômeno do traço flutuante; e que agora a TO orienta a pesquisa na direção de estruturas marcadas e dos reparos possíveis, além de evitar o problema da duplicação de generalizações e consegue expressar diretamente, pela orientação para o output, as partes da gramática que conspiram para a realização de certas estruturas superficiais. Quanto a mim, o fato de eu ter acompanhado as mudanças teóricas e procurado entender o que elas implicam, mesmo discordando de certos aspectos dessas teorias, muito contribuiu para o meu entendimento da arquitetura sonora das línguas e para a minha formação como fonólogo. Me parece que para o futuro, como no passado, o desafio é se dar conta de que a fonologia trata de conhecimento estrutural e que a aprendizagem da língua envolve abstração. Quer dizer, o fato de /t,d/ se fricativizarem frente ao /i/, embora seja explicado plausivelmente pela fonética, pode muito bem ser um fato irrelevante na aprendizagem da língua pela criança, que aprenderia igualmente a regra menos "natural" que faz passar $/ \mathrm{k} / \mathrm{a}[\mathrm{kx}]$ frente a /a/ ou /p/a $[\mathrm{pf}]$ frente a /o/. Consequentemente, não vejo a relevância de uma restrição na gramática sincrônica que se refere a fatos que explicam as mudanças históricas dos sons. Ao mesmo tempo, o desafio é de ver até que ponto conseguimos reconciliar as regularidades estruturais (morfo)fonológicas estebelicidas pelos fonólogos com as observações da fonética instrumental, por exemplo, para testar o caráter categórico ou gradiente de um processo, ou a plausibilidade de um traço fonológico específico ou de certa representação lexical ou derivada proposta, e com os achados da fonologia experimental para verificar se as generalizações (morfo)fonológicas são produtivas, semi-produtivas, ou improdutivas, ou se o grau de produtividade varia de um (grupo de) falante(s) para outro.

Agostinho, Rech: Você acredita que o trabalho descritivo tem sido preterido em relação à elaboração de teorias? Qual a sua opinião sobre isso?

W. Leo Wetzels: Suponho que com "trabalho descritivo" vocês querem dizer o estudo de línguas que ainda não foram (suficientemente) documentadas. Se for isto, a minha resposta é negativa. O trabalho teórico é muitas vezes praticado com base na língua materna ou com base em uma língua na qual o pesquisador possui uma competência (quase) 
nativa. Nesse caso, o próprio conhecimento e intuição do linguista pode fornecer os fatos sobre os quais ele baseia suas análises e arguições teóricas. $\mathrm{O}$ trabalho teórico também pode ocorrer com base em línguas bem documentadas que não são a língua nativa do pesquisador, como tem sido feito há séculos com relação às línguas "clássicas", como o sânscrito, o grego clássico e o latim. As condições e os meios para realizar trabalhos teóricos valiosos estão, portanto, amplamente presentes. No entanto, com isso, não quero dizer que a descrição de línguas não-documentadas ou insuficientemente documentadas não seja uma tarefa importantíssima. Qualquer língua não escrita que desaparece possivelmente constitui uma oportunidade perdida para ampliar nosso conhecimento sobre as diferenças e semelhanças entre as línguas e até talvez para alcançarmos a resposta à questão do porquê as diferenças e semelhanças observadas entre as línguas existem. Toda língua morta restringe o domínio empírico da linguística. Tenho muito respeito pelos linguistas que dedicam parte de suas carreiras a documentar línguas não documentadas, não só porque fornecem novos dados para testar teorias, por eles próprios ou por outros pesquisadores, mas também porque dão aos falantes dessas línguas a oportunidade de ler e escrever a própria língua, o que, por sua vez, contribui para a sobrevivência dessas línguas e das culturas das quais elas fazem parte. Afinal, é sobretudo a diversidade que torna o mundo bonito e fascinante, tanto em termos da natureza quanto da cultura. Qualquer pessoa que contribui para a sua preservação merece elogios.

Agostinho, Rech: Durante sua carreira, você fez pesquisas e orientou diversas dissertações e teses que envolviam trabalho de campo. Na sua opinião, qual é a importância da experiência e da metodologia de campo para os pesquisadores?

W. Leo Wetzels: Pessoalmente, não tive a oportunidade de realizar um longo trabalho de campo. Juntamente com o antropólogo Edwin Reesink (UFPE) e uma enfermeira da FUNASA [Fundação Nacional de Saúde] de Vilhena, fiz uma viagem cansativa no final do século passado pelas aldeias dos índios Nambikwara em Rondônia e Mato Grosso, para identificar, com base em uma lista de palavras pré-compilada, os principais grupos dialetais, a fim de escolher, com base em alguns critérios, as línguas que íriamos descrever no projeto Nambikwara. Nesta experiência, aprendi o quanto difícil podem ser as circunstâncias nas quais o trabalho de campo precisa ser realizado e passei ainda mais a respeitar os alunos que ficam meses no campo em difíceis circunstâncias. É claro que uma preparação metodológica adequada é necessária para realizar com sucesso este tipo 
de trabalho. Eu tinha a vantagem de que quase todos os alunos que trabalhavam comigo sobre línguas indígenas da América do Sul eram cidadãos de um país sul-americano e desfrutaram de um bom treinamento na metodologia do trabalho de campo nas universidades do país de origem. Afinal, todos eles tinham escrito uma dissertação de mestrado sobre uma língua indígena, ou realizado pesquisas antropológicas nas aldeias. Talvez esta pergunta, que parece um pouco com a anterior, também se refira à importância relativa da linguística descritiva em comparação com a teórica. Quero deixar claro que minha apreciação concerne igualmente a ambas as atividades. Um avião já não é construído por uma pessoa ou por dois irmãos, como o fizeram Santos Dumont e os irmãos Wright, o que ainda era possível no início do século XX. Tanto a tecnologia moderna quanto a ciência subjacente se tornaram muito mais complicadas. As pessoas têm competências diferentes e o progresso do nosso conhecimento deve-se principalmente à discussão científica e à cooperação entre pessoas com diferentes competências. A questão não é diferente no que diz respeito à linguística: os descritivistas e os teóricos precisam uns dos outros.

Agostinho, Rech: Além das pesquisas sobre português brasileiro e línguas indígenas brasileiras, você trabalhou com línguas crioulas de base portuguesa. Como surgiu o interesse por essas línguas? Quais foram os aspectos que você pesquisou?

W. Leo Wetzels: Esta pergunta me traz de volta ao problema do acento primário no PB. $\mathrm{O}$ meu interesse nas línguas crioulas de base portuguesa se originou na minha curiosidade de saber como a regra do acento primário funciona nestas línguas, pela seguinte razão: se a regra funcionar como no PB e não houver bons argumentos para definir, para aquelas línguas, uma vogal temática como morfema independente, então não existiria a possibilidade de as línguas crioulas terem uma regra baseada na estrutura $\left./ . ..]_{\text {raiz }}+\mathrm{V}\right]_{\text {tema }} /$ para a localização do acento principal, como foi proposto por alguns fonólogos para o PB, como alternativa a uma regra fonológica sensível ao peso silábico. Com esta pergunta na mente, olhei para três línguas crioulas diferentes, Kristang (Malacca Creole Portuguese) (BAXTER, 1988), Korlai (Guaro Creole Portuguese) (CLEMENTS, 1996) e Batticaloa (Batticaloa Creole Portuguese) (SMITH, 1978). As regras de acento do Korlai e do Batticaloa se mostraram muito diferentes da regra do acento português, mas ao mesmo tempo muito interessantes. Por isso decidimos analisar os acentos nestas línguas, assim como a maneira com que eles interagem com processos fonológicos (WETZELS; HERMANS, 2014; 2016). O Kristang acabou por ser a língua que eu estava procurando. 
Baxter (1988, p. 40) diz: "It appears that rules for stress placement have to apply to syntactic classes: e.g. verbs are stressed on the final syllable, nouns are stressed on the prefinal syllable if ending in a vowel, on [the] final syllable if ending in a consonant." ${ }^{1}$ Até onde pude observar, não há bons motivos para assumir que no Kristang existem vogais temáticas. Se a regra do acento proposta por Baxter para esta língua estiver correta, e acho que está, então podemos assumir que no PB há mesmo uma generalização baseada em peso para a colocação do acento principal, como registrei em Wetzels (2003).

Agostinho, Rech: No ano passado, foi publicado o livro "The Handbook of Portuguese Linguistics”, organizado por você, Sergio Menuzzi e João Costa. Poderia nos contar como foi a organização desse livro e falar sobre os capítulos em que você atuou?

W. Leo Wetzels: Quando Wiley-Blackwell me deu a oportunidade de editar um livro sobre o português na série "The Handbook of <Language $>$ Linguistics”, pensei que era uma oportunidade imperdível para apresentar a linguística portuguesa em um pódio internacional e em uma série de prestígio. Por causa do tamanho do trabalho e das limitações do meu próprio conhecimento, procurei a ajuda de Sergio Menuzzi e João Costa, que se mostravam tão entusiasmados quanto eu. A escolha dos temas discutidos no livro foi determinada em consulta uns com os outros, e também nos inspiramos nos volumes sobre outras línguas já publicados na Série. Como cada tópico precisava contemplar, quando necessário, as diferenças entre PE [português europeu] e PB, buscamos para cada capítulo uma co-autoria de especialistas de cada uma das duas variantes. Conseguimos alcançar este objetivo em quase todos os capítulos. Juntamente com Luiz Carlos Schwindt escrevi o capítulo sobre a fonologia e a morfologia da flexão, assunto sobre o qual ambos havíamos escrito anteriormente. A pedido de Gisela Collichon, fiquei como co-autor do capítulo sobre a sílaba, uma vez que a co-autora portuguesa, escolhida originalmente, havia se retirado. O capítulo sobre a sílaba é o último estudo fonológico escrito por Gisela. Por um tempo, todos nós acreditamos que ela poderia superar a doença. Minha tristeza foi grande quando ficou claro que nosso otimismo era ilusório. Com a Gisela, o Brasil não só perdeu um dos seus melhores fonólogos, mas também uma personalidade excepcional.

\footnotetext{
1 Tradução nossa: "Parece que regras para atribuição de acento devem ser aplicadas em classes sintáticas: verbos são acentuados na sílaba final, nomes são acentuados na penúltima sílaba se terminados em vogal e na última se terminados em consoante".
} 
Agostinho, Rech: Você se aposentou recentemente da Vrije Universiteit Amsterdam, na Holanda. Atualmente, como professor titular na UFC, quais são seus projetos?

W. Leo Wetzels: É verdade, não tenho mais nenhuma obrigação administrativa em relação à Universidade Livre, embora eu ainda esteja oficialmente associado a ela como pesquisador. Estou feliz com isso. Não gosto de reuniões e nunca me interessei por cargas administrativas. Sempre estive ocupado o suficiente com linguística. Ainda me sinto jovem para a aposentadoria, embora eu seja capaz de relativizar a importância da linguística para minha vida e também do meu próprio papel nela. Há bastante jovens talentosos para assumir as tarefas da minha geração. Continuo trabalhando por um tempinho, porque gosto e porque minha experiência ainda pode trazer algo positivo para os alunos. Ainda oriento seis estudantes de doutorado e, além dos meus próprios interesses, pelo fato de ser editor-chefe da Probus e assistente editorial do IJAL, continuo fazendo leituras de uma grande variedade de assuntos linguísticos. Meu trabalho na UFC me permite manter o contato com alunos, e espero que esse convívio estimule alguns deles para o mergulho no estudo da fonologia. Além disso, junto com Aline da Cruz, posso prestar serviço aos índios Tapeba que vivem nos arredores de Fortaleza e que estão interessados em aprender a falar nheengatu. Estando em Fortaleza, também tenho a chance de estudar mais de perto alguns assuntos fonológicos pouco claros dos dialetos do Nordeste. Por fim, com meus colegas da UFC, vemos quais temas podemos abordar conjuntamente, também levando em consideração os interesses dos alunos.

\section{Referências}

BAXTER, A. N. A Grammar of Kristang (Malacca Creole Portuguese). Pacific Linguistic Series B-No. 95. Department of Linguistics. Research School of Linguistic Studies. The Australian National University, 1988.

BERMÚDEZ-OTERO, Ricardo. Stratal Phonology. In S.J. Hannahs \& Anna R. K. Bosch (eds.), The Routledge handbook of phonological theory, 100-134. Abingdon: Routledge, 2018 .

. In defence of underlying representations: Latin rhotacism, French liaison, Romanian palatalization. Probus, 30:2, 2018. No prelo.

CHOMSKY, Noam; HALLE, Morris. The sound pattern of English. New York: Harper \& Row, 1968.

CLEMENTS, J. C. The Genesis of a Language. The Formation and Development of Korlai Portuguese. Amsterdam, John Benjamins, 1996. 
GRAU SEMPERE, A. Conflicting Quantity Patterns in Ibero-Romance Prosody. Doct. Diss. University of Texas at Austin, 2006.

GUSSENHOVEN, C.; JACOBS, H. Understanding Phonology. Fourth edition. London: Routledge, 2017.

HERMANS, B.; WETZELS, W. L. Productive and Unproductive Stress Patterns in Brazilian Portuguese, Revista Letras \& Letras, Uberlândia, V. 28, N. 1, p. 77-114, jan./jun. 2012.

HOOPER, J. An Introduction to Natural Generative Phonology. New York: Academic Press, 1976.

KIPARSKY, P. How Abstract is Phonology? In: FUJIMURA, O. (ed.) Three Dimensions of Linguistic Theory. TEC Company, Ltd. Tokyo, 1983, p. 5-56.

SMITH, I. R. Sri Lanka Creole Portuguese Phonology. Dravidian Linguistics Association. Tolkappiyar Hall, Kerala Paanini Buildings, Vanchiyoor, Trivandrum. India, 1978.

WETZELS, W. L. On the Weight issue in Portuguese, a Typological Investigation. Letras de Hoje, V. 38, N. 4, p. 107-134, 2003.

- Primary Stress in Brazilian Portuguese and the Quantity Parameter. In: ELORDIETA, G.; VIGÁRIO, M. (eds.) Journal of Portuguese Linguistics, Vol 5/6, Special Issue on the Prosody of the Iberian Languages, p. 9-58., 2006,

. Syllable Weight, Stress, and the Neutralization of Vowel Length in Batticaloa Creole Portuguese. In: NÚÑEZ-CEDEÑO, R. (ed.) The Syllable and Stress: Studies in Honor of James W. Harris. Walter de Gruyter, Berlin., 2016. p. 315-331.

WETZELS, W. L.; HERMANS, B. Branchingness and Stress in Korlai Portuguese. In: KAGER, R.; GRIJZENHOUT, J.; SEBREGTS, K. (eds.), Where the Principles Fail. A Festschrift for Wim Zonneveld on the Occasion of his 64th Birthday. Published by UIL OTS, Utrecht, 2014. p. 77-88.

WETZELS, W. L.; COSTA, J.; MENUZZI, S. The Handbook of Portuguese Linguistics. Malden: Wiley-Blackwell, 2016.

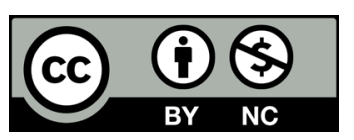

